\title{
Megaprojects Front-End Planning: The Case of Brazilian Organizations of Engineering and Construction
}

\author{
Otávio Mansur Motta, Osvaldo Luiz Gonçalves Quelhas, José Rodrigues de Farias Filho, \\ Sérgio França, Marcelo Meiriño \\ Department of Production Engineering, Laboratory of Technology, Business Management and Environment, \\ Fluminense Federal University, Rio de Janeiro, Brazil \\ Email: otaviomansur@hotmail.com, quelhas@latec.uff.br, fariasfilho@gmail.com, sfranca01@gmail.com, \\ marcelo@latec.uff.br
}

Received 20 June 2014; revised 16 July 2014; accepted 26 July 2014

Copyright (C) 2014 by authors and Scientific Research Publishing Inc.

This work is licensed under the Creative Commons Attribution International License (CC BY). http://creativecommons.org/licenses/by/4.0/

cC) (7) Open Access

\begin{abstract}
The goal of this study is to analyze the adoption of the Front-End Planning method by Brazilian companies which is applied in megaprojects management. For this reason, a survey was conducted with Brazilian companies of different sectors related to Engineering and Construction in order to perceive the adequacy and the frequency of the use of the Front-End Planning method and compare the theory with the market practices. From the eight topics raised to compare the theoretical reference with the organizational practices, only two topics presented relevant differences that need to be investigated in future researches. Among these differences between what is considered in the literature and what is practiced by the companies, it is possible to point out the variations in the project budgets in contrast with the methodology proposal to increase the cost predictability.
\end{abstract}

\section{Keywords}

Project Management, Organizational Strategy, Front-End Planning

\section{Introduction}

Despite the development of numerous project management and governance techniques, most large enterprises still fail to meet all their expected results. PricewaterhouseCoopers (PWC) [1] conducted a study in 2005 looking at the large capital projects in the world's mining industry. The study found that, when evaluated on their scope, cost, schedule, and business benefits, only $2.5 \%$ of them could be defined as successful projects. 
In the oil and gas industry, the results are not so different. It is estimated that about $30 \%$ to $40 \%$ of the projects have cost and/or implementation overruns that exceed 10\% (Mckenna, Vanderschee \& Wilczynski, 2011) [2].

For many years, the focus of project management has been to complete a project by performing deliveries and satisfying stakeholders-a focus that revolved around such factors as time, resource management, costs, and quality (Levine, 2005) [3]. However, completing projects and meeting all these requirements does not necessarily represent an organization's business success. Some researchers felt that focusing on managing projects in their most strategic aspects could make a major contribution to the analysis of their performance (Shenrar, 2007) [4].

Traditional methods of project management are sometimes inappropriate in the context of complex and uncertain projects. Such an assertion is borne out by studies on the attributes of complexity and uncertainty in project management carried out by such researchers as Morin (2006), Whitty and Maylor (2009), Shenhar and Dvir (2007), Hertogh and Westerveld (2010), Baccarini (1996), Maximian (2008). How the success of a project is evaluated depends, for one thing, on how it aligns with the company's business strategy (Shenrar \& Dvir, 2007) [4].

In this context, it is possible to identify a greater focus on the design phase of megaprojects, in which the strategic execution definition, cost estimates, selection of alternatives and preliminary analysis of engineering occur. Many authors agree that the Front-End Planning is the key to the success of a project (GIBSON et al., 2011; SMITH, 2000) [5] [6].

Cleland and Ireland (2002) [7] define the Front-End Planning as the process of analyzing and explaining the goals and strategies needed to drive the project to a successful end throughout its life cycle. To Samset and Williams (2010) [8], the Front-End Planning begins with the conception of the project, information generation and consolidation of the views of stakeholders, and ends with the final decision whether the project will be executed or not.

Whereas an international perspective, the Front-End Planning has been studied from different methodologies, which are spread mainly through specialized consulting firms. The Independent Project Analysis (IPA) and the Construction Industry Institute (CII), for example, are organizations that have extensive researches in this area.

In Brazil, many companies have also adopted this method due to the current situation of the country, characterized by the increasing number of large projects, which involve high levels of uncertainty and complexity. This fact, in turn, is a result of the rapid rise of emerging economies, especially the BRICS (Brazil, Russia, India, China and South Africa). Such economies tend to make large investments in housing, infrastructure and industrialization that are intensive in the use of minerals, metals and energy, which justifies the need to implement a lot of megaprojects.

However, the adoption of the Front-End Planning by Brazilian companies is not a research subject of many studies, despite being an emerging issue in the country and having gained great importance in the area of project management. The majority of these studies are not able to show actual results that the adoption of this method is bringing to the Brazilian companies. There is also the need to make a diagnosis of which sectors of the economy are applying this method, how often and based on which methodologies. The mapping of these features could enable a more critical reflection about this method, besides providing inputs for future research.

The importance of this paper can also be understood by the expansion of knowledge on the subject as well as the enrichment of literature, describing practices predominantly applied in the industry, which today are conditioned by the individual efforts of companies across the country. It is expected that the results obtained in this study can contribute to organizations think about their mega-enterprises management model and improve the management of their projects with a focus on strategic alignment.

Thus, this paper intends to contribute to knowledge in the field of Front-End Planning with emphasis in Brazil, offering the following general research objective: to analyze the adoption of the method of Front-End Planning applied in the management of megaprojects related to Engineering and Construction by Brazilian companies.

To achieve this, the study will carry out the following specific objectives:

- Conduct field research on Brazilian companies from assorted sectors involved with, either directly or indirectly, large Engineering and Construction projects, so as to verify how they perceive the adequacy and frequency of their use of the Front-End Planning method;

- Compare the information obtained in the theoretical framework with actual field research, via questionnaires, with regard to the identified key factors and business practices. 


\section{Literature Review}

Studies by Kwak and Anbari (2009) [9] in the area of management, and Crawford, Pollack and England (2006) [10] in the community of project management show that the adhesion of projects with their business strategies is the subject that is more prominence in recent years. These authors analyzed several journal articles present in an annual ranking of America's Financial Times, which includes: The Academy of Management Journal (AMJ), Management Science (MS), Harvard Business Review (HBR), California Management Review (CMR), Strategic Management Journal (SMJ), Journal of Operations Management (JOM), among others. This analysis also included articles published in the International Journal of Project Management (IJPM), in the Project Management Journal (PMJ) and in the Institute of Electrical and Electronics Engineers (IEEE).

Within this context, the Front-End Planning showed up as one of the main mechanisms used to ensure project alignment with business strategy.

This statement can be supported by a bibliometric survey conducted in the second half of 2011, using a combination of search arguments "Project Management”, "Strategic Alignment” and "Strategy”. The document type was restricted to articles; the year of publication restricted to between 2007 and 2011; the language to English, Portuguese, or Spanish; the subject area engineering, business, and management. As a result, a lot of publications were available: 657 publications in ISI platform, 990 in the Scopus and 20 in the SciElo.

To set the boundaries of the subject's approach, engineering and construction projects were focused on. Such a selection precluded a majority of available publications, articles considering new product development or Information Technology (IT) projects. It was also prioritized articles published in journals that have above classification of B2 in WebQualis CAPES ranking.

An analysis of titles and brief summaries of the reading and content narrowed down the amount of material most likely to fall within the desired context for this study, a selection of 27 articles. These articles are described at [11].

Of this total, over $50 \%$ cited at least once, the Front-End Planning as a way to achieve compliance of the project with the business strategy.

The industry employs different classifications in referring to the Front-End Planning method, as is pointed out by Back, Bell, and George (2008) [12], and Cho, Gibson, Pappas, and Wang (2006) [13]. Most of these references are such terms as: Pre-Project Planning (PPP), Front-End Planning (FEP), Front-End Loading (FEL), FrontEnd Development (FED), Front-End Engineering Design (FEED) and Front-End Decision Making (FEDM). Despite the assorted names, their underlying concept is basically the same. The names are meant to indicate that the time and resources available in the pre-project planning will dictate how the future goes (Merrow, 2011) [14].

For IPA (2011) [15], FEL is the process by which a company translates its technology and market opportunities into capital projects. The purpose of FEL is to align project goals with business needs and to develop the most efficient execution plan to achieve the project objectives.

CII (1995) [16] defines FEP as the process of developing sufficient strategic information with which you can define project risks and decide how to allocate resources to maximize your chances of success.

Costa Junior (2010) [17] states that experts commonly divide industry activities involving Front-End Planning into three main phases. Phase 1 aims to define business objectives, identify investment opportunities, and develop alternatives. At this stage, a company starts developing a business plan, an economic evaluation, a market forecast, competitive studies, and initial cost estimates. Phase 2 is when a company selects the best alternative identified in Phase 1, both for the site and for technology and acquisition strategy. At this stage, the main settings for conceptual engineering are performed, the trade-offs studied, and the project's economic data refined. Phase 2 marks the point where the project's scope is fixed. Phase 3 expands the detailing of the alternative selected in Phase 2, develops the implementation plan, and prepares the final estimates of cost and schedule. In this phase, engineers carry out the development of basic engineering, equipment specification, and a plan for supplies.

As was true with what the literature calls Front-End Planning, the literature assigns numerous names to these three phases. Although the process is similar in most industries, the names of the stages vary from organization to organization and/or author to author. Some examples of the nomenclature found in the literature are presented in Table 1.

Each phase has a set of deliverable products to be developed by the project team before the next step. To 
Table 1. Examples of nomenclatures for the three phases of the Front-End Planning method.

\begin{tabular}{cccc}
\hline Source & Phase 1 & Phase 2 & Phase 3 \\
\hline IPA (BARSHOP, 2009) [18] & FEL 1-Business Planning & FEL 2-Scope Development & FEL 3-Project Planning \\
CII (INGRAM, 2009) [19] & FEP 1-Feasibility & FEP 2-Concept & FEP 3-Detailed Scope \\
Shell (WEIDE, 2008) [20] & FED 1-Assess & FED 2-Select & FED 3-Define \\
ChevronTexaco (OKORO, 2005) [21] & Identify & Select & Develop \\
Petrobrás (FIGUEIREDO, 2008) [22] & Opportunity Identification & Alternative Selection & Project Definition \\
Vale (COSTA JÚNIOR, 2010) [17] & Business Analysis & Alternative Selection & Construction and Operation \\
Anglo Coal e Xstrata Coal & & & Planning \\
(PWC, 2008) [23] & Concept & Pre-feasibility & Feasibility
\end{tabular}

assess whether a project is ready to move from one phase to the next, the project team uses a mechanism for periodic checks called the gate process. The gate process represents the time in which the project should be approved for its next phase, and in which it may be returned to be better defined or be canceled. Its objective is to legitimize every stage of project development (Costa Junior, 2010) [17].

The model proposed by CII [24] describes the main activities to be developed in each phase, providing specific documents to detail them. This description is found in a guide called Front-End Planning ToolKit [25]. To measure the project's scope definition, in 1996 a tool was created for industrial projects called the Project Definition Rating Index (PDRI). It consists of a checklist of 70 scoping elements divided into 3 sections and 15 categories (Gibson, 2004) [26]. The elements are classified according to a setting level ranging from 0 to 5 , with 0-not applicable; 1—complete definition; 2-minor deficiencies; 3-some deficiencies; 4-major deficiencies; and 5-incomplete or poor definition. For each definition level, there is a score that, in terms of importance, differs from element to element. The score of each element is defined by the expertise of the group of professionals who participated in the creation of this tool. The maximum score, the sum of all categories, is 1000 points. The lower the score, the better the project is defined.

The FEL model proposed by the IPA [15] describes the minimum products required for each phase according to each discipline. To quantify the degree of project definition and to measure its performance, the IPA is one of the main maturity indices of the FEL index. The IPA, according to Barreto, Borges, Ferreira, Lopes, and Zucco (2006) [27], consists of three items: locational factors, definition of engineering, and Project Execution Plan (PEP). Each item is measured on a scale of 1 to 4,1 being the greatest degree of development and four being the most incipient. The FEL index is the weighted average score of these three items, a score ranging from 1 to 10 , where the lower the score, the greater the degree of maturity of the project.

A key point to highlight is that the importance of Front-End Planning method is not that it has essentially guided the dissemination of new concepts in project management literature, but rather that it organizes and systematizes existing concepts and is capable of promoting synergy between them.

The method incorporates the Front-End Planning practices outlined in the Project Management Body of Knowledge (PMBOK) [28]. Furthermore, it enables the addition of other practices and specific tools, such as Earned Value, Value Improving Practices (VIPs), quality management tools, reengineering techniques, and others.

Finally, a great deal of the material available on this methodology is restricted mostly to IPA and CII institutes. IPA offers a range of educational programs in the field of capital project implementation and evaluation. Companies wishing to improve the performance of their capital projects often hire IPA's services, thereby gaining access to some of their materials. CII also sells several products describing best practices, though at prices mainly affordable only to its members.

Nevertheless, the Front-End Planning method is gaining significant ground through its dissemination in scholarly works by professionals who, on a day-to-day basis, deal with it in their organizations. This methodology represents a practical complement to the Project Management Institute (PMI), which improves the life cycle of building megaprojects and contributes to making projects more competitive. 


\section{Research Methodology}

In order to confront theory with marketplace experience, a field study was developed, facilitated by a questionnaire that recorded practitioners' perceptions about the method's use.

The questionnaire was designed using Qualitrics site, which enables researchers to create online questionnaires. The profile of participants sought to be surveyed were companies that worked directly or indirectly with the deployment of large engineering projects. These projects would involve the construction of such projects as mines, ports, power plants, railways, roads, power grids, telecommunications, and so forth. The survey responses would reflect the knowledge of the persons designated by these companies to represent them.

In selecting the research population, Brazilian companies were chosen that had participated in PMI's 2011 annual report [29] and that had been working on large engineering projects. Drawing on a world contained in PMI's report can be justified given that PMI is today's leading institute in developing the field of project management; moreover, it comprises the principal organizations of Brazil. The focus on Brazilian companies was already explained in the introduction of this paper. Thus, this study certainly includes, as a part of its defined population, any major company in Brazil that uses PMI best practices.

Participating in the national report of the 2011 edition of pmsurvey.org, an annual survey organized by volunteer groups associated with PMI, were 754 organizations in Brazil. Of these, approximately $16 \%$ belonged to sectors involved in large engineering projects. Thus, the study's target population consisted of 121 separate companies, represented by appointed professionals and eligible to receive the study's questionnaire.

To seek information from each member of the population would be neither practical nor feasible, making it necessary to come up with a sample. Rea and Parker's (2000) formula [30] enables researchers to determine a sample size for variables expressed as proportions considering small populations. Based on Equation (1), it is possible to determine the number of responses appropriate to allow researchers to generalize to the entire population based on the results obtained from the questionnaire.

$$
\mathrm{n}=\frac{\mathrm{Z}^{2}[\mathrm{p}(1-\mathrm{p})] \mathrm{N}}{\mathrm{Z}^{2}[\mathrm{p}(1-\mathrm{p})]+(\mathrm{N}-1) \mathrm{C}^{2}}
$$

where $\mathrm{n}$ represents the sample size; $\mathrm{C}$ the precision or maximum permissible error in terms of proportions; $\mathrm{Z}$ the confidence level in standard deviation units (desired range); $p$ the proportion of the universe (probability of response); $\mathrm{N}$ the number of individuals in the population. To this formula, the following parameters were applied: $\mathrm{C}=10 \%=0.1, \mathrm{Z}=1.96 \%$ to $95 \%, \mathrm{p}=50 \%=0.5, \mathrm{~N}=121$.

As a result, it would take a sample of 53.79 valid questionnaires to ensure a confidence level of $95 \%$ on the validity of the sample, with an error margin of $+/-10 \%$. The questionnaire was sent to all 121 companies. Therefore, all elements of the population had the same probability of being selected to compose the sample. So, the sampling can be classified as probabilistic.

\section{Analysis and Discussion of Research Findings}

Between July and September 2012, questionnaires were sent to the 121 companies. Of the 70 questionnaires answered, 16 were discarded for being incomplete, leaving 54 that were considered valid (and thus reaching the necessary sample). The results from the questionnaire were treated by descriptive and analytical statistics.

\subsection{Sample: Profile of Organizations}

There is a large concentration of responses from companies in the sectors of engineering and construction (35\%), oil and gas (28\%), and mining and metals (24\%). It is worth mentioning that the classification "companies in engineering and construction" refers to companies dedicated exclusively to designing, managing, or carrying out works, or companies preparing conceptual designs-basic and detailed. The other companies, although also involved in the area of engineering, have specific products as core businesses and thus do not fall in this category.

Most of the companies (61\%) that responded to the questionnaire are developing projects with costs averaging over $\$ 100$ million, evidence of their large size. Of these $61 \%, 22 \%$ are companies developing so-called megaprojects, projects whose budgets, according Merrow (2011) [14], exceed \$1 billion.

It was also discovered that $26 \%$ of the sample established engineering projects with durations averaging beyond four years, $22 \%$ with a duration averaging under a year, $20 \%$ between two and three years, $17 \%$ between 
one and two years, and $15 \%$ between three and four years. In this context, it appears that the organizations' profiles and their types of projects accurately reflect the current situation in the world of business.

\subsection{Sample: Profile of Respondents}

The profile of the sample respondents is primarily composed of engineers (89\%), followed by administrators (6\%) and economists (2\%). The preponderance of engineers was expected since a prerequisite for filling out the questionnaire was working in companies directly or indirectly involved with the development and/or implementation of engineering and construction projects.

Most of these professionals held no managerial position (represented by $44 \%$ ), with $33 \%$ being functional leaders, $17 \%$ project leaders and $6 \%$ directors. The majority (57\%) had more than five years of experience in project management, reflecting the fact that most of the respondents possessed a significant level of knowledge regarding this area.

Regarding work experience with their current organization, however, there seemed to be an opposite effect to the time worked in the field of project management with a majority (57\%) having less than five years with their companies. This may result in not-fully-developed perceptions about the corresponding organization.

\subsection{The Application of the Front-End Planning Method}

It was found that $67 \%$ of respondents knew only one method for evaluating individual projects having multidisciplinary characteristics: the Front-End Planning method. This result is presented in Figure 1.

Figure 2 shows the profiles of companies that know and apply the main method for assessing identified individual projects.

An analysis of Figure 2 reveals the following:

- Taken as a whole, professionals unaware of the Front-End Planning method belong mostly to the engineering and construction sector (50\%) and to firms whose projects have an average duration of less than one year (42\%).

- Taken as a whole, companies that apply the Front-End Planning method belong mostly to the mining and metals (40\%), and oil and gas (30\%) sectors. They are commonly companies that develop projects with a budget averaging over \$100 million (70\%) and an implantation time averaging over two years (77\%).

- Taken by individual sectors, almost all the companies in mining and metals (92\%) know and apply the method. In the oil and gas sector, $87 \%$ of the companies are familiar with the method and $60 \%$ actually apply it.

- Looking at project costs, it appears that projects averaging between \$10 million and \$100 million most often apply the methodology (83\%), followed by projects exceeding $\$ 1$ billion (75\%).

- Looking at project implementation time, in projects lasting more than three years, the methodology is used $73 \%$ of the time.

Confirming what was found in the literature review, the field study demonstrated that the companies that use Front-End Planning method are those developing projects having high investment costs and long life cycles, and this is especially true in the oil and gas sector and the mining and metals sector.

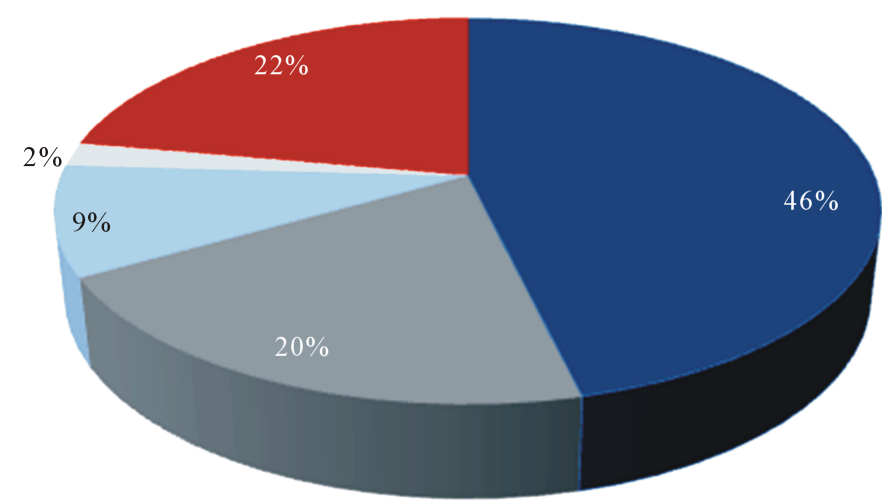

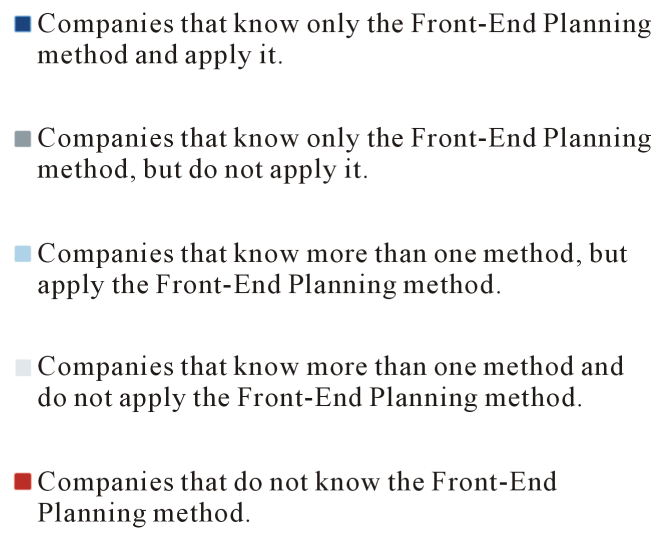

- Companies that know only the Front-End Planning method and apply it.

Companies that know only the Front-End Planning method, but do not apply it.

Companies that know more than one method, but apply the Front-End Planning method.

Companies that know more than one method and do not apply the Front-End Planning method.

Companies that do not know the Front-End Planning method. 
Another result obtained from the survey was that of the companies who know the Front-End Planning method, $40 \%$ of their representatives believe in it fully and $50 \%$ believe that, in most cases, this method is essential to aligning projects with their company's business strategy. This result is shown in Table 2.

According to Rea and Parker (2000) [30], it is useful to include measures of central tendency in the frequency distribution table to enlarge the description of the data presented. These measures are statistics that provide a number of features summarizing what is "typical" or "average" for the data. The three main measures of central tendency are the mode, median, and arithmetic mean. In the case of Table 2, such data are ordinal in nature, the median is found at position 22, which is contained in the "partially agree".

However, the Likert-type scale permits to associate numerical values with ordinal data, enabling the researcher to calculate the arithmetic mean. For each category of ordinal nature, a numerical value (from 1 to 5) was assigned; 1 represented "disagree completely" and 5 "agree completely.” Thus, it is assumed that an equal distance exists between each category of variable, a distance measurable by the numerical value assigned to the corresponding category. The average then is estimated at 4.21, neighboring the category of "agree completely" in the "partially agree" category. Hence, the average provided more information than the median, indicating that the center of the distribution is close to "partially agree" (median), yet something is weighted towards the response category "strongly agree".

Of the companies who know Front-End Planning method, 90\% of their respondents know only the IPA and CII models, verifying that these models are the most studied and disseminated of those in the field of project management. Of the $67 \%$ of respondents who know the method, $56 \%$ apply it in the day-to-day running of their organizations. It is worth noting, then, that it is still the method used predominantly by the industry to evaluate

\begin{tabular}{|c|c|c|c|c|c|c|c|c|c|c|c|c|c|c|c|c|c|}
\hline \multirow{2}{*}{\multicolumn{3}{|c|}{$\begin{array}{l}\text { Knowledge about the Front-End } \\
\text { Planning method }\end{array}$}} & \multicolumn{5}{|c|}{ Sector of the organization } & \multicolumn{5}{|c|}{ Average cost of project } & \multicolumn{5}{|c|}{ Average duration of project } \\
\hline & & & $\begin{array}{l}\tilde{J} \\
\tilde{J} \\
\bar{\Xi} \\
\overline{0}\end{array}$ & 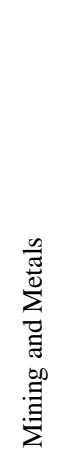 & 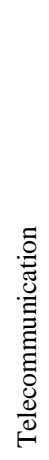 & 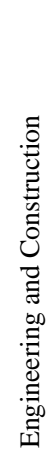 & $\begin{array}{l}\mathscr{0} \\
\stackrel{D}{0}\end{array}$ & 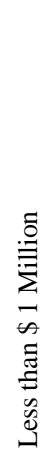 & 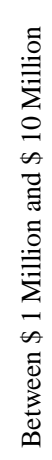 & 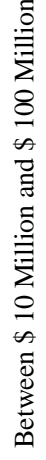 & 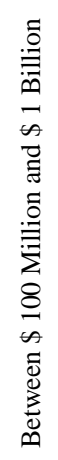 & 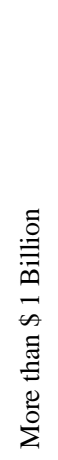 & 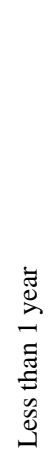 & 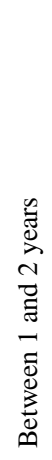 & 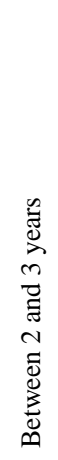 & 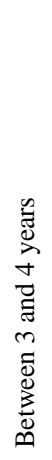 & 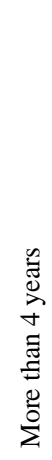 \\
\hline Do not know & 12 & $22 \%$ & 2 & 1 & 1 & 6 & 2 & 4 & 1 & 0 & 6 & 1 & 5 & 1 & 3 & 0 & 3 \\
\hline Know but do not apply & 12 & $22 \%$ & 4 & 0 & 1 & 6 & 1 & 3 & 3 & 1 & 3 & 2 & 3 & 5 & 1 & 2 & 1 \\
\hline Know and apply & 30 & $56 \%$ & 9 & 12 & 0 & 7 & 2 & 1 & 3 & 5 & 12 & 9 & 4 & 3 & 7 & 6 & 10 \\
\hline Total & 54 & $100 \%$ & 15 & 13 & 2 & 19 & 5 & 8 & 7 & 6 & 21 & 12 & 12 & 9 & 11 & 8 & 14 \\
\hline
\end{tabular}

Figure 2. Profile of companies that know and/or apply the Front-End Planning method.

Table 2. Impression concerning the method of Front-End Planning for the project alignment with organizational strategy.

\begin{tabular}{|c|c|c|c|c|c|}
\hline Impression & Value & Frequency (f) & Percentage (\%) & f Cumulative & f Average \\
\hline I disagree completely & 1 & 1 & $2 \%$ & 1 & 1 \\
\hline I partially disagree & 2 & 2 & $5 \%$ & 3 & 4 \\
\hline Indifferent & 3 & 1 & $2 \%$ & 4 & 3 \\
\hline I partially agree & 4 & 21 & $50 \%$ & 25 & 84 \\
\hline I agree completely & 5 & 17 & $40 \%$ & 42 & 85 \\
\hline Total & & 42 & $100 \%$ & & 177 \\
\hline
\end{tabular}


individual projects. Of the 30 companies applying Front-End Planning method, 57\% use the IPA model, 7\% use the CII model, and $27 \%$ use both. The remaining $10 \%$ use custom models designed by the companies themselves.

All these figures may give an impression that the companies are satisfied with this method in practice. However, the expectations of organizations are not always being met as describe in Figure 3.

Figure 3 shows that, with regard to the average a project goes over the initially planned budget, the view of most companies is pessimistic. 67\% of respondents say projects utilizing Front-End Planning method go over budget, and $50 \%$ report an overflow above $10 \%$.

Looking at individual sectors, $89 \%$ of companies in oil and gas who completed the questionnaire and $75 \%$ of those in mining and metals indicate they are failing to meet their budgets. The fact that companies in engineering and construction realize less the impact of costs is likely due to two main reasons:

- The contract of the service provider may be based on the use of man/hours and therefore warranted additional costs are passed on to the customer, i.e., the project owner.

- In Brazil, large projects in engineering and construction generally use a form of the Engineering, Procurement and Construction (EPC) contract, in which the owner of the enterprise usually defines the basic design and contracts all the other stages through completion. The contractor, in turn, must deliver the work prepared and operational. In this case, the contractor can be compensated for possible cost increases through other types of gain, since he is responsible, for example, for purchasing materials and equipment.

Regarding work being done on schedule, companies seem to be more optimistic about the Front-End Planning method. A majority of respondents (57\%) said that projects using this method could always or in most cases meet the initial deadline. Looking at individual sectors, however, $71 \%$ of companies in engineering and construction meet their deadlines in a minority of cases.
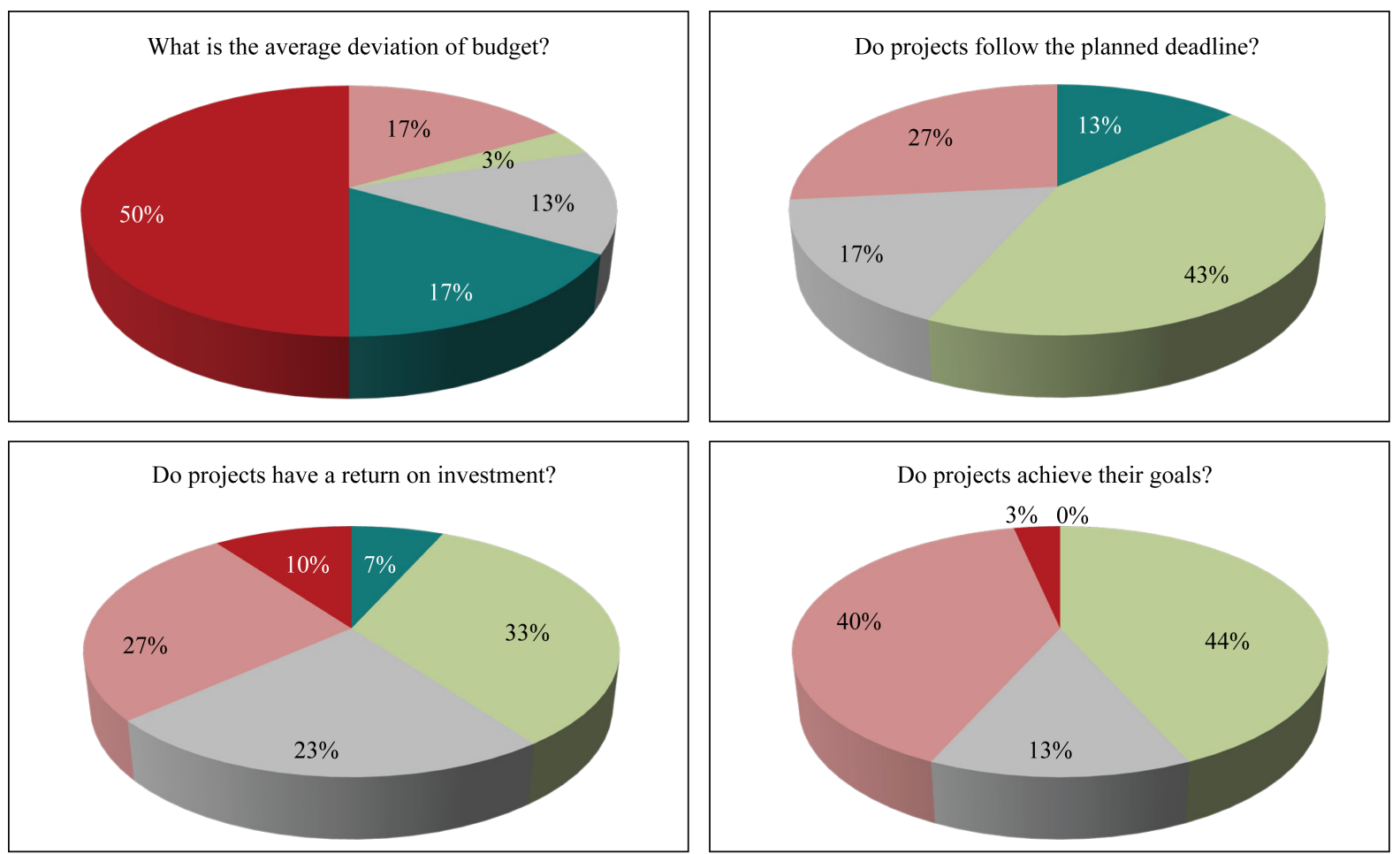

Always/Saving of over to $10 \%$

Most times/Savings up to $10 \%$

About half the time/No relevant deviation

In a minority of cases/Overflow up to $10 \%$

Never/Overflow of over $10 \%$

Figure 3. Performance of the projects that apply Front-End Planning method. 
As noted in the survey, the fact that these companies encounter delays is probably due to the nature of their core businesses, which is running the project. In most cases, the owner of the enterprise is not the performer itself. The owner hires designers, builders, and managers. Therefore, the owner of the project (usually companies in mining and metals, oil and gas, petrochemical and chemical, telecommunications, among others) encounter less delay in projects. Engineering and construction companies work within tighter scopes and tighter deadlines to meet the needs of their customers. The owners of the enterprises, on the other hand, have a wider scope; any delay of an activity can be offset by anticipating another, thus generating a different perception about completion schedules.

Respondents were divided regarding the achievement of general goals such as, the time, cost, quality and customer satisfaction (internal or external). Less than half (43\%) believed such goals are met a minority of the time or never, while the same proportion (43\%) believed that it occurred most often. There was also a fairly even split regarding the perception of return on investment in the project, with $40 \%$ saying they always or most of the time attain the return or benefits expected, while $37 \%$ take the other view, seeing only a minority of cases yielding the desired return.

To some extent these results contradict the notion that the proposed method provides, by and large, greater predictability of costs and deadlines and assigns competitiveness to projects. One factor that may explain this issue is organizations inadequately implementing the method. Such a determination, however, is not the focus of this research.

Finally, to identify whether a correlation existed between the variables, some joint distributions were analyzed. A major goal of building a joint distribution of two variables is to describe the association between them, that is, when one wishes to know the degree of dependency between them, so that a person can predict the outcome of one by knowing the achievement of the other (Medri, 2011) [31].

Table 3 presents the relative frequencies for the misuse of the budget within the deviation, which are obtained by setting column totals at $100 \%$.

An examination of Table 3's data reveals that, regardless of the delay in projects, most companies (67\%) usually spend more than planned. With distributions differentiated by average deviation of term, a well-marked disparity is apparent in the percentages. There is a greater concentration of budget deviation only when the time deviation is also frequent. This result signifies that, for the sample considered, there is dependence between the variables.

Other correlations were also performed to check the joint behavior of other variables, such as: "average cost of project" × "mean deviation of budget" and "average time of project" × "mean deviation of term". The first aimed to identify whether a budget overflow occurs usually on projects that cost more. The second aimed to verify that projects having longer durations more often present schedule overruns. In both two-dimensional analyses, it was concluded that the variables were associated.

\subsection{Comparative Table}

To summarize key comparisons between the results obtained in the literature and the field research, Table 4 is presented.

Table 3. Joint distribution of relative frequencies (in percentage) in relation to the total of each row of variables: mean deviation of time and average deviation of budget.

\begin{tabular}{|c|c|c|c|c|c|c|c|}
\hline & & \multicolumn{6}{|c|}{ Average deviation of budget } \\
\hline & & $\begin{array}{l}\text { Saving of } \\
\text { over } 10 \%\end{array}$ & $\begin{array}{c}\text { Savings } \\
\text { up to } 10 \%\end{array}$ & $\begin{array}{c}\text { No relevant } \\
\text { deviation }\end{array}$ & $\begin{array}{l}\text { Overflow } \\
\text { up to } 10 \%\end{array}$ & $\begin{array}{c}\text { Overflow of } \\
\text { over } 10 \%\end{array}$ & Total \\
\hline \multirow{5}{*}{$\begin{array}{c}\text { Mean deviation } \\
\text { of time }\end{array}$} & In a minority of cases & $25 \%$ & $13 \%$ & $25 \%$ & $25 \%$ & $13 \%$ & $100 \%$ \\
\hline & About half the time & $0 \%$ & $0 \%$ & $20 \%$ & $40 \%$ & $40 \%$ & $100 \%$ \\
\hline & Most times & $8 \%$ & $0 \%$ & $8 \%$ & $8 \%$ & $77 \%$ & $100 \%$ \\
\hline & Always & $50 \%$ & $0 \%$ & $0 \%$ & $0 \%$ & $50 \%$ & $100 \%$ \\
\hline & Total & $17 \%$ & $3 \%$ & $13 \%$ & $17 \%$ & $50 \%$ & $100 \%$ \\
\hline
\end{tabular}


Table 4. Comparison between the results obtained in the literature and field research.

\begin{tabular}{|c|c|}
\hline Items analyzed & Bibliographic search results \\
\hline $\begin{array}{c}\text { (1) } \\
\text { Methods for } \\
\text { evaluation of } \\
\text { individual projects }\end{array}$ & $\begin{array}{l}\text { Given the selected articles dealt with in the } \\
\text { bibliometric analysis, the methods } \\
\text { most often cited are: } \\
\text { - Individual methods: financial methods } \\
\text { (NPV, IRR, Payback), and methods of risk } \\
\text { analysis (Monte Carlo simulation); } \\
\text { - Multidisciplinary Methods: only the } \\
\text { Front-End Planning method. }\end{array}$ \\
\hline $\begin{array}{l}\text { (2) } \\
\text { Importance of } \\
\text { Front-End } \\
\text { Planning method }\end{array}$ & $\begin{array}{l}\text { The purpose of the method is to align project } \\
\text { goals with business needs. The work done in } \\
\text { the initial phase of the project may influence } \\
\text { its outcome by selecting the best projects, } \\
\text { eliminating wrong projects and selecting } \\
\text { the most appropriate scope. }\end{array}$ \\
\hline $\begin{array}{l}\text { (3) } \\
\text { Dynamics of } \\
\text { Front-End } \\
\text { Planning method }\end{array}$ & $\begin{array}{l}\text { In this method, it is common to divide the } \\
\text { development stages of a project into three } \\
\text { phases. Each phase has a set of deliverable } \\
\text { products to be developed by the project team } \\
\text { before the next step. To assess whether a } \\
\text { project is able to move from one phase to } \\
\text { the next, a mechanism is used for periodic } \\
\text { checks, called Gate Process. }\end{array}$ \\
\hline $\begin{array}{l}\text { (4) } \\
\text { Target audience } \\
\text { of Front-End } \\
\text { Planning method }\end{array}$ & $\begin{array}{l}\text { Projects with high investment costs and long } \\
\text { life cycles, primarily in such sectors as } \\
\text { petrochemical \& chemical, oil \& gas, } \\
\text { mining \& metals, pulp \& paper and others. }\end{array}$ \\
\hline
\end{tabular}

(5)

Methodologies or models

Performance over time

Performance against cost

(8)

Performance in relation to return on investment and success in general project
The IPA and CII are the two institutes with extensive research on this method, each having developed their models.

According to the IPA, FEL, if implemented well, can cause a project to be up $4 \%$ faster than the industry average. In extreme cases, it can reduce the deployment time by approximately $20 \%$. For CII, FEL can make a design up to $1 \%$ faster than the average.

According to the IPA, FEL, if implemented well, can cause a project to be $7 \%$ cheaper than the industry average. In extreme cases, it can reduce the total project cost by about 20\%. For CII, FEL, if implemented well, can cause a project to be as much as $3 \%$ cheaper than the average.

According to the IPA, FEL can make improvements to a project so that its IRR values are up as much as $3 \%$.

According to the IPA, about $60 \%$ of megaprojects that ranked the scale of FEL as "best" are successful. About $50 \%$ of megaprojects that ranked the FEL Index as "good" are successful.

Results of field research

Similar results?

Regarding the multidisciplinary tools, $67 \%$ of the companies that responded to the survey only know the Front-End Planning method. $11 \%$ knew this methodology, as well as other methods such as Lean Project Delivery System (LPDS), Ziel-Projekt Orientierte Planung (ZOPP) or Planning and Project Evaluation by Objectives, Project In the Controlled Environment (PRINCE) and peers reviews.

$40 \%$ of respondents completely believe and $50 \%$ just believe that, in most cases, this method is essential for strategic alignment.

$48 \%$ believe completely and $36 \%$ just believe that in most cases there are clearly defined processes in the method to be followed.
92\% of companies in Mining \& Metals apply the method;
$60 \%$ of companies in Oil and Gas apply the method;
$73 \%$ of respondent companies that develop projects lasting more than three years apply the methodology;
$75 \%$ of respondent companies that develop projects over $\$ 1$ billion apply the method.

Of the companies who know this method, $90 \%$ of respondents know only the IPA and CII models.

Most respondents (57\%) said that projects that apply this method can achieve the planned deadline always or most cases.

$27 \%$ said that they could reach the deadline in a minority of cases and $17 \%$ in half the time.

$67 \%$ of respondents say the projects that apply the Front-End Planning method in their respective companies spend more than planned, and $50 \%$ report an overflow budget above $10 \%$.

$40 \%$ of respondents say they always or most of the time attain the expected return, while $37 \%$ see a minority of cases yielding the desired return. $43 \%$ of respondents believe that they achieve the overall goals of time, cost, quality, and customer satisfaction less than half the time or never, while $43 \%$ believe that it occurs most often.
NO (need further research to investigate the causes)

PARTIAL (need new research to investigate the causes) 


\section{Conclusions}

The goal of this study was to analyze the adoption of the method of Front-End Planning applied in the management of megaprojects related to Engineering and Construction by Brazilian companies. As a result, it was found that Front-End Planning is applied by $56 \%$ of the companies. It is most often applied in companies developing projects with budgets averaging above $\$ 100$ million and with an average implantation time of over two years; these are mainly in the sectors of mining and metals (40\%), and oil and gas (30\%). Most companies using Front-End Planning follow the IPA and/or CII models.

However, despite the possible impression that the companies were satisfied with this method in practice, the study found that the expectations of organizations were not always being met. $67 \%$ of respondents say projects utilizing Front-End Planning method go over budget. Respondents were divided regarding the achievement of general goals such as, the time, cost, quality and customer satisfaction (internal or external). Less than half (43\%) believed such goals are met a minority of the time or never, while the same proportion (43\%) believed that it occurred most often. There was also a fairly even split regarding the perception of return on investment in the project, with $40 \%$ saying they always or most of the time attain the return or benefits expected, while $37 \%$ take the other view, seeing only a minority of cases yielding the desired return.

Looking at individual sectors, $71 \%$ of companies in engineering and construction fail to meet their deadlines. This is because they are, in most cases, the one carrying out the project. On the other hand, the owners of these projects (usually companies in mining and metals, oil and gas, among others) are the ones to most often notice budget overruns, as any additional costs are usually passed along to them. Thus, the study highlights a contradiction between one of the major theoretical propositions of this methodology (which is to give greater predictability of cost and deadlines) and the results obtained in the research.

The study also achieved its original specific objectives. As evidence that these objectives were met, Table 4 was produced in Section 4.4; it summarizes the main comparisons between the results collected from the literature and field research.

Taking all this into account, this work has contributed to the improvement of the life cycle of construction projects by highlighting the design stage of large projects. The design stage develops strategic studies, defines viability, describes the attractiveness of the business, estimates preliminary costs, manages risk, and produces a preliminary analysis of engineering alternatives.

This study limited itself to investigating the following key factors: project alignment with business strategy, practices predominantly applied, and the perceptions of Brazilian organizations regarding Front-End Planning. This study's objective is to investigate whether companies are implementing Front-End Planning properly or to find possible causes of problems faced by these companies.

It is suggested as future work to examine how the Front-End Planning method is being applied in organizations so as to possibly explain certain observed contradictions between theory and practice revealed by this paper. Another suggestion is to create models, complementary to existing ones, for other megaprojects that are being undertaken because they align with organizational strategy. The CII and IPA models could still be applied in an ongoing project to verify similarity between the maturity levels obtained using the two models.

Thus, this study adds a different perspective to the traditional approaches to project life cycles. It emphasizes pre-planning as an additional tool to support the decision-making process, one that maximizes the chances of success with projects.

\section{References}

[1] Pricewaterhous Coopers (2005) Project Portfolio Management: A Study of 200 Organizations and 10.046 Projects. PWC Publications, Brisbane.

[2] Mc Kenna, M.G., Wilczynski, H. and Vandershee, D. (2011) Capital Project Execution in the Oil and Gas Industry. http://www.boozallen.com/media/file/Capital_Project_Execution.pdf

[3] Levine, H.A. (2005) Project Portfolio Management: A Practical Guide to Selecting Projects, Managing Portfolios, and Maximizing Benefits. John Wiley \& Sons, San Francisco.

[4] Shenhar, A.J. and Dvir, D. (2007) Project Management Research: The Challenge and Opportunity. Project Management Journal, 38, 93-99.

[5] Gibson Jr., G.E. and Cho, C.S. (2011) Building Project Scope Definition Using Project Definition Rating Index. Journal of Architectural Engineering, 7, 115-125. 
[6] Smith, C. (2000) Improved Project Definition Ensures Value-Added Performance. Hydrocarbon Processing, 79, 95-99.

[7] Cleland, D.I. and Ireland, L.R. (2002) Project Management: Strategic Design and Implementation. McGraw-Hill, New York.

[8] Samset, K. and Williams, T. (2010) Issues in Front-End Decision Making on Projects. Project Management Journal $(P M J)$, 41, 38-49.

[9] Kwak, Y.H. and Anbari, F.T. (2009) Analyzing Project Management Research: Perspectives from Top Management Journals. International Journal of Project Management (IJPM), 27, 435-446. http://dx.doi.org/10.1016/j.ijproman.2008.08.004

[10] Crawford, L., England, D. and Pollack, J. (2006) Uncovering the Trends in Project Management: Journal Emphases over the Last 10 Years. International Journal of Project Management (IJPM), 24, 175-184. http://dx.doi.org/10.1016/j.ijproman.2005.10.005

[11] Motta, O.M. (2013) Estudo de Práticas com Ênfase na Estratégia Empresarial para a Gestão de Megaprojetos: O Caso das Organizações Envolvidas com Engenharia e Construção. M.Sc. Thesis, Production Engineering Department, Federal Fluminense University, Niterói.

[12] Back, W.E., Bell, L.C. and George, R. (2008) Critical Activities in the Front-End Planning Process. Journal of Management in Engineering, 24, 66-74.

[13] Cho, C.S., Gibson Jr., G.E., Wang, Y. and Pappas, M.P. (2006) What Is Preproject Planning, Anyway? Journal of Management in Engineering, 22, 35-42.

[14] Merrow, E.W. (2011) Industrial Megaprojects-Concepts, Strategies and Practices for Success. John Wiley \& Sons, Incorporated, Hoboken.

[15] Independent Project Analysis (IPA) (2011) http://www.ipaglobal.com

[16] Construction Industry Institute (CII) (1995) Pre-Project Planning Handbook. Publicação 39-2. Austin.

[17] Costa Jr., W. (2010) Metodologia FEL—Programa de Capacitação para Líderes de Projeto de Capital. Valer-Educação Vale, Brazil.

[18] Barshop, P. (2009) Incomplete FEL 2-Destroyer of Capital. Independent Project Analysis Newsletter. Independent Project Analysis, Inc., Ashburn.

[19] Ingram, C.B. (2009) The Supervising Discipline Engineer`s (SDE) Role in the Front End Planning Process. M.Sc. Thesis, Department of Civil, Construction \& Environmental Engineering, the University of Alabama, Tuscaloosa.

[20] Weijde, G.A.V.D. (2008) Front-End Loading in the Oil and Gas Industry. Towards a Fit Front-End Development Phase. A M.Sc. Thesis, Faculty Technology, Policy and Management, Delft University of Technology, Delft.

[21] Okoro, B. (2005) Chevron Project Development and Execution Process (CPDEP)—Overview Presentation to NSE. Nigerian Society of Engineers, Abuja.

[22] Figueiredo, J.A. (2008) Benchmarking em Projetos de Produção de Petróleo e Gás Natural. A Experiência da Petrobrás. Conferência da Organização Nacional da Indústria do Petróleo, Rio de Janeiro.

[23] Couchman, J., Gillespie, B. and Steffen, A. (2008) Avoiding Cost Blow-Outs and Lost Time on Mining Capital Projects through Effective Project Stage Gating. PricewaterhouseCoopers Publications, Brisbane.

[24] Construction Industry Institute (CII) (2011) https://www.construction-institute.org

[25] Construction Industry Institute (CII) (1997) Front-End Planning Tools: PDRI and Alignment. Publication 113-1. Austin.

[26] Gibson Jr., G.E. (2004) Project Definition Rating Index. Construction Industry Institute, University of Texas, Austin.

[27] Barreto, F.C.P., Borges, J., Ferreira, J.C.A., Lopes, R.H. and Zucco, L.A.O. (2006) Utilização de Ferramentas para Melhoria do Planejamento no Gerenciamento de Projetos de Grande Porte na Petrobrás. MBA Thesis, Department of Administration, Faculdade de Administração, Economia e Contabilidade da Universidade de São Paulo (USP), São Paulo.

[28] PMI (2008) PMBOK Guide: A Guide to the Project Management Body of Knowledge. 4th Edition, PMI, Newtown Square.

[29] Pmsurvey.org: A Global Initiative of PMI Chapters. Relatório Nacional. (2011) http://www.informal.com.br/pmsurvey/?page id=160

[30] Rea, L.M. and Parker, R.A. (2000) Metodologia de Pesquisa: Do Planejamento à Execução. Pioneira, São Paulo.

[31] Medri, W. (2011) Análise Exploratória de Dados. Centro de Ciências Exatas. Departamento de Estatística, Universidade Estadual de Londrina, Paraná. 
Scientific Research Publishing (SCIRP) is one of the largest Open Access journal publishers. It is currently publishing more than 200 open access, online, peer-reviewed journals covering a wide range of academic disciplines. SCIRP serves the worldwide academic communities and contributes to the progress and application of science with its publication.

Other selected journals from SCIRP are listed as below. Submit your manuscript to us via either submit@scirp.org or Online Submission Portal.
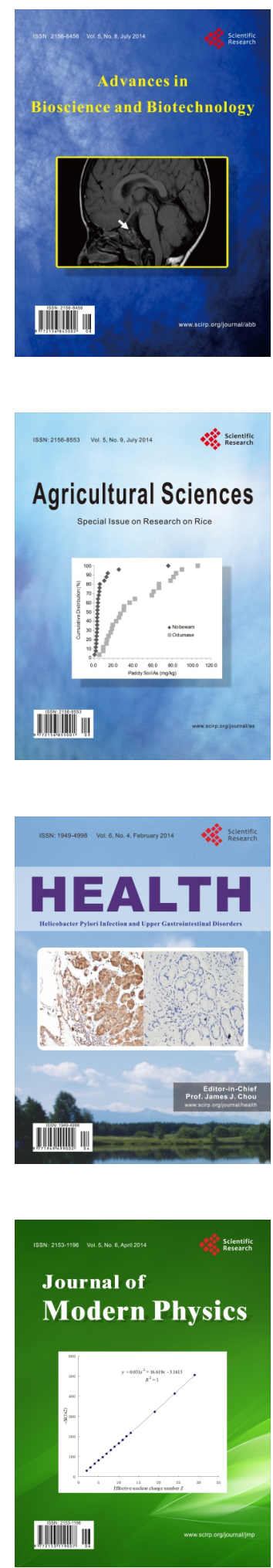
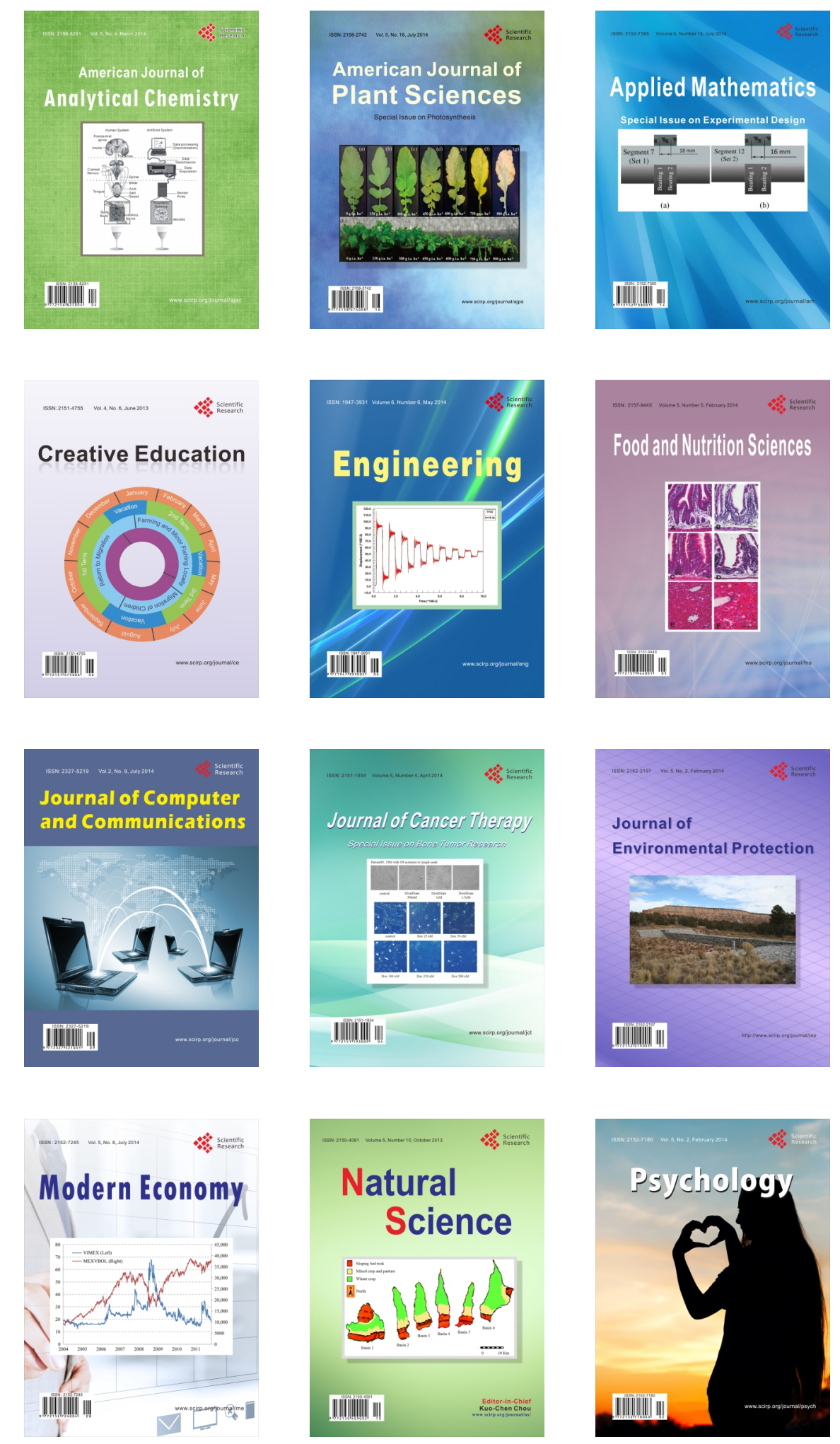